\title{
A Corpus-Driven Analysis of Explicitness in English as Lingua Franca
}

\author{
Serap Önen ${ }^{1, *} \&$ Dilek İnal ${ }^{1}$ \\ ${ }^{1}$ Hasan Ali Yücel Faculty of Education, Istanbul University- Cerrahpaşa, Istanbul, Turkey \\ *Correspondence: Hasan Ali Yücel Faculty of Education, Istanbul University- Cerrahpaşa, Istanbul, Turkey. E-mail: \\ onens@istanbul.edu.tr
}

Received: July 4, 2019

Accepted: July 27, 2019 Online Published: August 5, 2019

doi:10.5430/jct.v8n3p73

URL: https://doi.org/10.5430/jct.v8n3p73

\begin{abstract}
This paper examines explicitness in English as lingua franca (ELF) spoken interactions. Using a conversation analysis procedure, about $11 \mathrm{~h}$ of audio-recorded naturally occuring ELF interactions of 79 incoming Erasmus students were analyzed for this purpose. The corpus was compiled by means of 54 speech events, 29 interviews and 25 focus group meetings and the participants represented 24 mother tongues. Research into ELF reveals that ELF speakers tend to use various "explicitness strategies" (Mauranen, 2007) in order to enhance intelligibility. The findings of this study show that there are indeed variations from standard ENL forms with respect to the degree of explicitness in spoken interactions. There is a tendency among ELF speakers to make the meaning more explicit for the listeners. Repetitions of same expressions in subsequent sentences, use of over-explicit forms, use of an extra subject following a relative clause and use of emphatic reference are the emerging patterns observed in this study.
\end{abstract}

Keywords: English as a lingua franca, explicitness, explicitness strategies, ELF spoken interactions

\section{Introduction}

English as lingua franca (ELF) have been defined as "a 'contact language' between persons who share neither a common native tongue nor a common (national) culture, and for whom English is the chosen foreign language of communication" (Firth, 1996: 240); as "a repertoire of different communicative instruments an individual has at his/her disposal, a useful and versatile tool, a "language for communication"” (House, 2003: 559); as "a medium of communication by people who do not speak the same first language" (Kirkpatrick, 2007a: 155); and as "a contact language used only among nonmother tongue speakers" (Jenkins, 2006a: 160). The one common point among these definitions of ELF is that English is perceived as the medium of communication among people coming from diverse mother tongues. Another point, which is open to discussion, is that ELF interactions exclude native speakers. As Seidlhofer (2011: 7) puts forward, this is not a very accurate definition as ELF interactions include Inner and Outer Circle English speakers as well, e.g. in an academic conference held in Seattle or at a touristic journey to India. She defines ELF as "any use of English among speakers of different first languages for whom English is the communicative medium of choice, and often the only option" (Seidlhofer, 2011: 7).

\subsection{Research into ELF}

The increase in global communication has been an important factor in the spread of English. English is a global lingua franca like no other. The number of its non-native speakers outweighs its native speakers. As Crystal (2003) puts forward ESL and EFL speakers will gain prestige and shape the future of English by creating their own standard varieties. Likewise, ELF speakers who come from diverse ethnic, linguistic, cultural and social backgrounds and use English as a medium of communication are expected to shape the future of English. These observations have greatly impacted the interest in ELF research. The studies in ELF can be broadly categorized as those describing the linguistic features of written and spoken ELF discourse; those investigating the attitudes and perceptions towards ELF; corpora studies; and those focusing on how to bring ELF into the classroom. The lexico-grammar of ELF has been investigated by Seidlhofer (2001, 2004); Dewey (2007a); Cogo and Dewey (2012); and Breiteneder (2009). The phonological characteristics of ELF have been examined by Jenkins (2000) and Walker (2010). The pragmatic features of ELF have been investigated by Björkman (2011a); Firth (1996); Firth and Wagner (1997); House (1999, 2002); Kaur (2011); Meierkord (2000); and Mauranen (2006a, 2006b). As for the attitudes towards ELF, Murray 
(2003); Jenkins (2005a); Llurda (2005); Young and Walsh (2010) identified teachers' -pre-service and in-serviceperceptions of ELF and Dalton-Puffer, Kaltenboeck and Smit (1997); Timmis (2002) and Groom (2012) examined students' perceptions of ELF. With respect to the corpus studies, VOICE (Vienna-Oxford International Corpus of English); ELFA (the Corpus of English as a Lingua Franca in Academic Settings); WrELFA (the Corpus of Written English as Lingua Franca in Academic Settings); ACE (the Asian Corpus of English) are among the large-scale ELF corpora which have been used as a source of data in ELF research. On the other hand, Kemaloglu-Er and Bayyurt (2019); Kaçar and Bayyurt (2018); Sifakis, Lopriore, Dewey, Bayyurt, Vettorel, Cavalheiro, Siqueira, and Kordia (2018); and Sifakis and Bayyurt (2016) have been carrying out studies on ELF-aware pedagogy and teacher education which can be used as a guide by English teachers who wish to bring ELF into their classrooms.

\subsection{Explicitness as an Emerging Pattern in ELF Interactions}

In a cooperative discourse the responsibility of participants is to ascertain the meaning. Meaning can be either speaker-oriented or hearer-oriented. The requirements of a speaker-oriented discourse are explicitness and clarity. In a speaker-oriented culture, if something is not comprehended in a specific speech event, the speaker is accused of not being clear and precise enough (Lakoff, 1984). However, in a hearer-oriented culture, imprecision is valued. When speakers are over-explicit, they are perceived negatively. Being very clear and straightforward is seen as contemptuous. Thus, while in a speaker-oriented culture, 'imprecision' is marked; in a hearer-oriented culture 'explicitness' is marked (Lakoff, 1984). This shows that different cultures have different norms in the expression of meaning.

In English as Lingua interactions, the participants come from diverse cultural backgrounds. When a speaker's native language is based on a different strategy from the language of other speakers this might create a problem. Therefore, it is important to understand how meaning is negotiated in ELF discourse. Previous pragmatic studies in ELF (Seidlhofer, 2004; Cogo \& Dewey, 2012; Mauranen, 2006b; Kaur, 2011) show that speakers use some negotiation strategies. Mauranen (2006b) in her ELFA-based study investigated the occurrence and prevention of misunderstandings among ELF speakers. The findings revealed that ELF speakers were successful in managing to prevent linguistic misunderstandings by means of explicitation strategies, repetitions, and collaborative tactics. Similarly, Kaur (2011) examining the self-repair practices of ELF speakers, reveals that correcting and using a variety of self-repair practices to make the meaning explicit and clear are among the emerging patterns in ELF interactions.

This paper primarily examines over-explicitness, e.g. "black color rather than just black", in spoken ELF interactions, which is revealed as a characteristic of ELF communication in previous ELF studies (Seidlhofer, 2004: 220) and addresses the following research question:

RQ: Does English as a lingua franca reveal any variations from standard ENL forms with respect to the degree of explicitness?

\section{Method}

This study is a part of a corpus study based on English as lingua franca interactions. The corpus, Corpus IST-Erasmus (Önen, 2014), is composed of 10 hours 47 minutes of audio-recorded naturally occuring ELF interactions and 93,913 words of transcribed data. One of the first papers (Önen, 2015) reporting the findings of Corpus IST-Erasmus was concerned with the use of prepositions in English as lingua franca interactions. The results show that there are variations from standard ENL forms in the way prepositions, e.g. ' $t o$, of, in, at, on, ...', are used. As proposed by Seidlhofer (2004: 220) and Cogo and Dewey (2012: 48), "[i]nserting 'redundant' prepositions, as in We have to study about ..." is observed as an emerging pattern in ELF interactions. Furthermore, omission of the prepositions in obligatory contexts, substitution of the standard prepositions by other prepositions and use of innovative prepositions are clearly emerging as well. Another study (Önen, 2016) based on Corpus IST-Erasmus was concerned with the marking system for 3rd person present tense in spoken ELF interactions. The results indicate that the use of 3rd person zero in place of 3rd person -s is widespread among ELF speakers as has been pointed out in previous ELF studies.

\subsection{Research Design}

This is a corpus study which investigates lexico-grammar of spoken ELF interactions. The main stages of compiling a spoken corpus are recording, transcribing, coding and mark up, and management and analysis (Adolphs \& Knight, 2010: 3). The data collection phase of this study started with the recording of the naturally occurring ELF interactions and lasted for three months. Then, the 10 hours 47 minutes of recorded data were transcribed verbatim 
following the transcription conventions of VOICE. One of the limitations during this process was that the existing software programs were not able to recognize non-native speakers' accents and convert voice into text accurately. Therefore, the transcriptions were performed manually. As the third stage, the raw transcriptions were marked and coded manually using the adapted form of VOICE mark-up conventions. The pronunciation variations, onomatopoeic noises and breath were not coded as they were not related to the scope of this study. As for the data analysis, the corpus was examined in two ways: manually and by means of corpus analysis software (WordSmith Tools 6.0).

\subsection{Participants and Setting}

The corpus was compiled with the participation of 79 exchange students, primarily Erasmus students, enrolled in state and foundation universities in Istanbul. Convenient and snowball samplings were employed and participation in the study was completely voluntary. However, the restrictive criterion was to be an incoming exchange student and to use English as a medium of communication with other students. As can be seen in Table 1, the 79 participants were of 24 different lingua-cultural backgrounds. Moreover, 6 of the participants were bilinguals.

Table 1. The Distribution of the Participants by Mother Tongues

\begin{tabular}{|c|c|c|}
\hline & Mother Tongues & No. of Speakers \\
\hline 1. & Arabic & 2 \\
\hline 2. & Azerbaijan & 1 \\
\hline 3. & Basque & 1 \\
\hline 4. & Bulgarian & 6 \\
\hline 5. & Cantonese & 2 \\
\hline 6. & Chinese & 1 \\
\hline 7. & Czech & 4 \\
\hline 8. & Danish & 1 \\
\hline 9. & Dutch & 7 \\
\hline 10. & French & 4 \\
\hline 11. & Gallician & 1 \\
\hline 12. & German & 19 \\
\hline 13. & Greek & 2 \\
\hline 14. & Italian & 7 \\
\hline 15. & Korean & 3 \\
\hline 16. & Lithuanian & 2 \\
\hline 17. & Mandarin Chinese & 1 \\
\hline 18. & Polish & 9 \\
\hline 19. & Portuguese & 1 \\
\hline 20. & Slovak & 2 \\
\hline 21. & Spanish & 3 \\
\hline 22. & Suriname & 1 \\
\hline 23. & Turkish & 4 \\
\hline 24. & Ukranian & 1 \\
\hline
\end{tabular}

The age range of the participants was 19-27 years. They were exchange students enrolled in various undergraduate or graduate programs in Istanbul. In total, the participants represented 10 universities, 4 state and 6 foundation universities. The majority of the participants were from Istanbul University. However, students from Yeditepe University and Bahçeşehir University also showed high participation in the study.

The setting for data collection was primariy Istanbul University but some of the speech events were conducted at Bilgi University, Yeditepe University, and Bahçeşehir University. Particularly, the international day organizations that took place at these foundation universities contributed immensely to the data collection process.

\subsection{Data Collection Instruments}

The corpus was compiled by means of 54 speech events, 29 interviews and 25 focus group meetings. The primary objective of these speech events was to encourage the participants to talk as much as possible. Each speech event was piloted before the actual study and necessary revisions were applied. 
The interviews were conducted on a face-to-face basis with one participant. The participants were asked to answer 15 open-ended questions impromptu. The questions were primarily based on participants' Erasmus experiences. The focus group meetings were also conducted on a face-to-face basis but with two participants. The participants chose a topic among the previously arranged list and discussed the topic impromptu. In order to avoid the use of native language, the pairs that would participate in the meetings were selected from different L1s. Prior to each speech event, the participants were given a participant information sheet and consent from and a participant information questionnaire. All the speech events were recorded using a digital voice recorder. By means of these speech events naturally occuring ELF interactions were audio-recorded.

\subsection{Data Analysis}

The corpus was analyzed both manually and electronically. First of all, the transcriptions of 54 speech events were transferred into a single file. Thereby, a 93,913 words corpus of spoken ELF was compiled. The next step was to create a word list of the corpus using the WordSmith Tools 6.0, a lexical analysis software. The software provides a word list of the corpus which displays the words in the corpus according to their frequency orders, gives the percentages of their occurences, and shows the distribution of the words in each speech event. Besides, the software enables to make concordance analyses, identify the collocations and clusters, and compare the corpus with other related corpora. However, the analysis of the explicitness in ELF interactions had to be performed manually because the software cannot detect explicit language uses in the corpus.

\section{Results}

The results reveal that over-explicitness is an emerging pattern in spoken ELF discourse as proposed in previous ELF studies. ELF speakers in this study do also attempt to make the meaning more explicit in the speech events. As in Cogo and Dewey (2012: 110) the speakers are "exceptionally listener-oriented in talk". The following extracts illustrate the over-explicitness observed in the interactions.

\section{Extract 1 (S11: German)}

$156 \mathrm{~S} 11: \mathrm{mhm}($.$) erm: i live in a: erm (.) flat share? a: little apartment i share it with$

157 a (.) turkish girl and it's in nisantasi? (.) erm it's a nice area i like it but erm i

158 found it o:ver a friend because a fellow student went to istanbul in two thousand

159 and nine and she erm heard that i need a apartment and she told me

$160<$ imitating $>$ yeah $<$ imitating $>\mathrm{i}$ know (.) a nice girl and maybe she is searching

161 for a flatmate (.) and so: erm she have had a free room and then we erm wrote at

162 facebook and so we LIKED each other and she said <imitating $>$ yeah you can

163 move $<$ imitating $>$ (.) into my flat and so we share this flat (.) and erm it's nice

164 living with her and it's so (.) good that she's a turkish girl and she can help me in

165 everything: and she: (.) she went to me with er to the mobile shops and things

166 like this so and we go out and she show me istanbul and (.) that's nice to live

$167<12>$ with $h e r</ 12>$

In this extract, an Erasmus student is talking about the process of finding a housemate. Although in line 157, the student states that she shares the flat with a 'Turkish girl', in 164 she uses the same expression again, though it would be appropriate to just say 'it's so good that she's Turkish'. As can be understood, the speaker's main concern is that her housemate is Turkish, not that she is a girl. Thus, the use of the word 'girl' following the word 'Turkish' shows the tendency for over-explicitness. Also, the use of 'meat' following 'pork' in line 41 in Extract 2, the use of 'school' preceding 'children' in line 2 in Extract 3, the use of 'language' following 'English' in line 39 in Extract 4, the use of 'country' following 'the other one' in line 36 in Extract 5, the use of 'language' following 'azerbaijani' in lines 171 and 175 in Extract 6, are just a few of the over-explicit forms attested in the corpus.

\section{Extract 2 (S21: Italian)}

39 S21: yeah i don't like meat here so much (.) because i like

40 S22: why

41 S21: i like you know pork meat so: you cannot find here $<6>$ easily $</ 6>$

42 S22: <6>@@@</6>@@

43 S21: actually when i: came back italy for for a while i: come here again with

44 some (.) you know sausage real sausage @

45 S22: yes but $<$ slow $>$ this is er (.) for their re $<7>$ ligion $</ 7><$ slow $>$ 


\section{Extract 3 (S23: Bulgarian)}

1 R: interview eleven (1) okay at what age do children start in your school

2 S23: back in bulgaria er children our school children start school at seven six

3 or seven years it depends on which part of the year they are born some parents

4 prefer to send them erm: (.) a bit: late: than usual

\section{Extract 4 (S25: German)}

$33 \mathrm{R}:<4>$ mhm yeah $\mathrm{i}</ 4>$ understood so maths courses history they are all in

34 german

35 S25: yes

36 R: $<5>$ okay $</ 5>$

37 S25: $<5>$ every $</ 5>$ thing is in german $i$ think it should be offered to be in english

38 (.) for knowing the parents decide okay maybe my children (.) should be learning

39 the english language $=$

$40 \mathrm{R}:=\mathrm{mhm}=$

41 S25: =much more (1) so but (1) it depends on the school and then the education

42 system

\section{Extract 5 (S50: Lithuanian)}

33 in the street where is: some place (.) m:aybe five people would stop and they will

34 try to help you so (.) what i'm trying to say: tha:t (.) this is the most important

35 thing for me when you're going to different country because you can see

36 differences between your own country and other one country (.) so: it's nice i like

\section{Extract 6 (S71: Azerbaijani)}

169 S71: $\mathrm{mhm}(1) \mathrm{my}($ (.) they are five (1) in my family father mother me (.) my sister

170 and brother and i'm the (1) older than them and erm we are speaking in

171 azerbaijani language but (1) sometimes i say to my mother to speak with me in

172 russian because her russian is (1) like russian or russian yes that's why i don't

173 want (.) to: have accent (1) and that's why i speak with her russian (.) or for (1)

$174 \mathrm{n}$ :ot to be in accent (1) in my speaking russian but (1) exactly we speak in (.)

175 azerbaijani language and (1) now $\mathrm{i}<@>$ miss them so much $<\mid @>$

Besides this, there is another emerging pattern of explicitness in the corpus, which does not appear in ENL varieties. That is, ELF speakers tend to use an additional subject following a relative clause. As can be seen in lines 7 and 9 in Extract 7, and in line 16 in Extract 8, the relative clauses 'some children who are little bit slow at learning', 'the students who are at the age of seven and five', and 'people who study economics' are followed by the subject pronoun 'they', which is not permitted in ENL.

\section{Extract 7 (S6: German, R: Turkish)}

5 S6: but there are some cases for example i was (.) really $<$ fast $>$ interested in

6 going to school so there are possibilities to go there $<$ fast $>$ with (.) at the age

7 of five or (.) for some children $<$ fast $>$ who are little bit slow at learning they

8 can also start at $</$ fast $>$ s:even but $i$ think six is still the usual (.) age

9 R: mhm but er the students who are at the age of seven and five they are not

10 included in the same class

11 S6: yes they are they are

\section{Extract 8 (S15: German)}

$14 \mathrm{R}: \mathrm{mhm}$ (1) what are the criteria to be accepted to the erasmus program in your

15 country

16 S15: that differs a lot so people who study economics they have to really have

17 to have good grades and then to apply to it formally but for me it was pretty easy 
The same pattern is also observed in reduced relative clauses, as presented below. In line 126 in Extract 9 and in line 67 in Extract 10 respectively, 'some of the gir:ls i met here' and 'my neighbor in harbiye' are followed by subject pronouns.

\title{
Extract 9 (S15: German)
}

125 S15: erm: yeah there are a few but less than i would expect so: erm (1) $\mathrm{i}$ think it

126 really depends: so some of the gir:Is i met here they stay at home all the time (.)

\section{Extract 10 (S27: German)}

66 S27: =experience yeah (.) erm (1) ye:s i know then it's weird cos (.) my neighbor

67 in harbiye he said that he always checks who likes his pictures and who doesn't

As can be seen, though not permitted in ENL varieties, ELF speakers combine relative clauses with subject pronouns for the sake of explicitness. Moreover, unlike ENL, there is high degree of explicitness in ELF interactions attained through the repetition of same words or phrases in subsequent clauses. For example, in line 288 in Extract 12, the speaker uses the word 'urology' in succeeding clauses, where an ENL speaker would most probably use the subject pronoun 'it'.

\author{
Extract 11 (S10: German) \\ $145 \mathrm{~S} 10:<15>\mathrm{hm}</ 15>\mathrm{i}$ sp- i: spea:k french? i had (.) i learned french in school (.) \\ 146 and $i$ think $i$ was quite good at it but i forgot a lot now and $i$ also had italian but \\ 147 italian just a little bit not very good er of course now i learn turkish (.) and that's:
}

\section{Extract 12 (S24: Greek)}

209 S24: and: (.) also the (.) i know it's a poor neighborhood but $i$ also like the

210 neighborhood because (.) it's there's life in it and some power for example

287 S24: erm yeah as i told we take circles of internships let's say like er (.) i just

288 for example i just finished my urology and i had the exam for urology=

\section{Extract 13 (S42: Dutch)}

$103 \mathrm{R}: \mathrm{mhm}$ (.) of all the courses you are taking this term which one interest you the

104 most (1) which course

105 S42: erm: (.) i think ecommerce (1) because ecommerce is: (1) a course (.) that's

106 really e:r (1) contemporary it's talks about nowadays issues (.) about the internet

\section{Extract 14 (S79: Czech)}

104 S79: yes: it's especially about religion (1) because for example here i'm (.) i

105 really miss the pork (1) because (.) muslims people (.) not eating the pork and (1)

106 and i'm now (1) three months before erm (.) three months erm (1) without pork

On the other hand, explicitness is also attained through the use of fronting structures. In fact, these structures are also widespread in ENL. As Carter et al. (2000: 159) put forward "[p]reposing or fronting identifies for a listener that a place, person, or event is important. It is common in spoken English in the form of heads, but some forms of fronting are also used in written English". The following sentences illustrate the use of heads in ENL.

John, he's nice.

The man from Leeds we met on holiday, his sister...

The results, they are interesting.

My friend, Janet, her sister has just emigrated to Brazil.

That leather coat, it looks really nice on you.

(Cartel et al., 2000: 156,169)

However, as Cogo and Dewey (2012: 110) state "[t]he degree to which speakers in ELF put this to use, though, does appear to be a distinctive interactional feature". The following extracts illustrate the same situation in Corpus IST-Erasmus. 


\section{Extract 15 (S3: Spanish)}

159 about er the secretary service of the universities $<@>$ my hometown $<\mid @>$

160 university they are working all all the days and the secretary you can ask

\section{Extract 16 (S5: Polish)}

162 good thing to do so (.) like lot of my friends they they're musicians they promote

163 their music also through facebook so like i just you know through links for like

\section{Extract 17 (S10: German)}

202 OLDER? (.) my brother he studies physics and my sister becomes er (.) like

203 kind- in the kinder- she works in the kindergarten (.) hm (1) so but they are (.)

\section{Extract 18 (S11: German)}

183 not english and erm (.) so: erm yeah we actually just speak in german (.) my

184 sister she is: erm nineteen and right now she's living in new zealand (.) so she

\section{Extract 19 (S14: Polish)}

76 S14: =e:r only when i spoke with foreigners because local people don't they don't

77 really knew english all that much

\section{Extract 20 (S17: Italian)}

166 S17: o:h i have got a two sisters (.) the smaller one erm she's seventeen years old

167 and of course she use facebook a lot (.) for everything for for (.) er read about his

In each of these extracts, the subjects are followed by subject pronouns. For example, in line 184 in Extract 18, the subject pronoun 'she' is used subsequent to the subject, as in 'my sister she is: erm nineteen...'. There are also several cases in the corpus where the reverse occurs; that is, pronouns are followed by subjects. As presented in the extracts below, in order to ensure comprehension, speakers use overt subjects, 'the topic', 'christians', 'Istanbul', 'little children', 'people', after the pronouns. It is obvious that speakers attempt to make the meaning more explicit for the listener.

\section{Extract 21 (S6: German)}

67 S6: er okay like here in turkey (.) er:m (.) with most of them $<$ slow $>$ i (.) do

68 speak (.) english $</$ slow $>$ especially if it (.) the topic is about (.) erm (.) yeah

$69<$ fast $>$ related to courses because $<$ /fast $>$ (.) my vocabulary (.) is not as

\section{Extract 22 (S9: Portuguese)}

114 here they are more religious than in spain and they are and then it's there is

115 different there is muslim men and the others christians so maybe that's: (.) a

116 different culture

\section{Extract 23 (S10: German)}

124 S10: hm: (.) < slow>first one it's SO: much more big</slow> it's HUGE istanbul

125 university in my university we have like (.) i think we have f:ive thousand

\section{Extract 24 (S16: German)}

7 S16: yeah it changes in the primary school there's when i was in school it was

8 only: german up to now they little children also have some english courses=

\section{Extract 25 (S74: Polish)}

73 S74: the biggest difficulty for us is the cultural difference (1) because (.) in here

74 (1) women covers themselves (.) and in europe we don't so sometimes (1) we:

75 people pay attention to us (.) even (.) though (.) we are not wearing for example 
Furthermore, repetitions are also very frequent in the corpus. ELF speakers, as illustrated with the following extracts, tend to repeat their utterances either to make sure that the listener understands or to emphasize the arguments made in the discourse.

\section{Repetitions}

\section{Extract 26 (S3: Spanish)}

150 don't like e:r $<$ fast $>i$ don't like too much from istanbul university that you don't

151 have $<$ fast $>$ e:r (1) too much space for too much space for practice sport (1) for

152 practice sport yeah (.) you know you don't ha:ve a football fie:ld you don't have

153 the spa:ce you don't have $<$ fast $>$ too much space for practice sport that i think is

154 important also for the students $</$ fast $>$ and for example in my hometown

\section{Extract 26 (S31: Polish) \\ 72 S31: $<$ loud $><3>$ children $</ 3></$ loud $>$ yes and (.) national (.) national holiday and \\ 73 they are children and we think hm: like in poland (1) it could be (.) like if there is \\ 74 national holiday (.) about (.) it was about making the (.) national holiday is like \\ 75 national holiday (.) it's really pathetic}

\section{Extract 27 (S33: Arabic)}

89 S33: yes is it the first time (.) i: i chosed also turkey because (.) i knew that there

90 was good weather@@@ $<@>$ so it's really good $</ @>$ to live in turkey (1) as today

91 is a really good day (.) and: (1) i also wanted (.) to: to discover this (1) cultural

92 turkish culture (1) turkish culture

Finally, as in Cogo and Dewey (2012: 110), "emphatic reference through frequent use of phrases" is also observed in Corpus IST-Erasmus. In particular, the extensive use of 'right now' is salient, as presented in Table 2. Consequently, in line with the previous studies (Dewey, 2007a; Cogo \& Dewey, 2012), the tendency for over-explicitness is an emerging pattern in Corpus IST-Erasmus. The use of over-explicit forms, e.g. 'pork meat'; the use of additional subjects in relative clauses, e.g. 'people who study economics they'; the high degree of explicitness attained through repetitions, e.g. 'i think ecommerce because ecommerce is'; the use of fronting structures, e.g. 'my brother he studies'; and repetitions are the primary means for ensuring explicitness in the corpus.

Table 2. The Concordance of 'Right Now'

\begin{tabular}{|c|c|}
\hline $\mathrm{N}$ & Concordance \\
\hline 130 & or not hm that's fine just enjoy yourself yeah right now and we'll you will see yeah are we done no almost \\
\hline 131 & a child it was fourth class at primary school right right now it's first class of primary school what are the \\
\hline 132 & up the the relationship with friends i mean we're right now in turkey and i'm from france and it's really useful \\
\hline 133 & already graduated and the one that we're living right now with is also graduated and working and he was he \\
\hline 134 & it was a flat apartment then we moved to sisli and right now we are living close to istiklal caddesi we all this \\
\hline 135 & that's not our thing right now it's just we have fun right now we'll see what will happen when i'm going back \\
\hline 136 & dig into spanish which becomes quite quite popular right now and $i$ think in the future it will be chinese and \\
\hline 137 & him as well so that's not yeah that's not our thing right now it's just we have fun right now we'll see what will \\
\hline 138 & were too much different but $\mathrm{i}$ don't know because right now $\mathrm{i}$ have a turkish boyfriend and when i'm going back \\
\hline 139 & was a child we were starting school at seven $\mathrm{mhm}$ right now it has changed and the children start going to school \\
\hline 140 & they think yeah $\mathrm{mhm}$ that was good at all $\mathrm{mhm}$ my right now is different also what do you think the daily life you \\
\hline 141 & there is one other things to do and but okay and right now the system is easy now $\mathrm{i}$ am agree $\mathrm{i}$ am agree what \\
\hline 142 & beneficial to to your education you are following right now $\mathrm{hm}$ you have to proof it prove yeah you have to \\
\hline 143 & a lot of time and it's not really something $\mathrm{i}$ can do right now so maybe at one point but it's not like $\mathrm{i}$ really really \\
\hline 144 & at one point but it's not like i really really need it right now yeah yeah your writing skills i think they're okay \\
\hline 145 & speak in german my sister she is erm nineteen and right now she's living in new zealand so she can speak english \\
\hline 146 & ge do children start school in your country right now there is er reform of education and this is some of \\
\hline 147 & but from what i've heard sometime ago for example right now er english is not even the er most used er language \\
\hline 148 & turkey mhm and er since i'm writing my thesis right now and my thesis is about er the events of september \\
\hline 149 & is much higher than hers and at here university right now they have worry about english teacher from what \\
\hline 150 & age do children start school in your country erm right now they're about five years old and six months so this \\
\hline 151 & that is one of the most interesting courses i follow right now $\mathrm{mhm}$ have you seen any differences between your \\
\hline
\end{tabular}




\section{Discussion}

The primary focus of this study was to investigate the degree of explicitness in ELF interactions. The findings suggest that there are variations from standard ENL forms with respect to the degree of explicitness in ELF interactions. As proposed by Seidlhofer (2004: 220) “[o]verdoing explicitness (e.g. black color rather than just black) is typical of spoken ELF interactions. First of all, speakers tend to make the meaning more explicit for the listeners. They repeat the same expressions in subsequent sentences, as in "i share it with a turkish girl ... it's so good that she's a turkish girl ...". Besides, as suggested in ELF literature, they use over-explicit forms, such as 'pork meat' rather than just 'pork'. Moreover, unlike ENL, there is a tendency in ELF interactions to add an extra subject following a relative clause, e.g. "people who study economics they have to ...". Furthermore, the use of fronting structures, which also appear in ENL, is widespread in the corpus, e.g. "my brother he studies physics ...". Finally, explicitness is also attained through repetitions, as in "too much space for too much space for practice sport for practice sport yeah ...", and through emphatic reference, e.g. 'right now'.

In summary, the study reveals that there are some emerging patterns in English as lingua franca interactions and over-explicitness is one of them. The results of this and other ELF corpora can be beneficial for the field of ELT and teacher education. First of all, one of the most important benefits of corpora studies is that they reflect real language use. They do not display prefabricated patterns or inauthentic language uses but the naturally occuring patterns and authentic language uses. Therefore, the findings of corpora studies should be applied to material development in language learning and teaching. On the other hand, as the mobility of students and teachers is promoted in the last decade universities have become multicultural environments. English is used as the medium of instruction not only in the classroom but also on the campuses. Thus, it is vital that an instructor lecturing in multicultural classes is aware of the emerging patterns in ELF interactions and design the course content, materials, and type of assessment accordingly.

In relation to limitations, this study is only based on lexico-grammar of spoken ELF interactions. Therefore, generalizations cannot be made regarding the written ELF interactions. Future research could investigate lexico-grammar of ELF in written interactions and digital media. Besides, in order to fully identify the features of ELF lexico-grammar, further studies investigating other lexico-grammatical units, such as tenses, modals, passives or if-constructions should be conducted.

\section{References}

Adolphs, S., \& Knight, D. (2010). Building a spoken corpus: what are the basics? In A. O'Keeffe \& A. McCarthy (Eds.), The routledge handbook of corpus linguistics, (pp. 38-52). Oxford, UK: Routledge.

Björkman, B. (2011a). Pragmatic strategies in English as an academic lingua franca: ways of achieving communicative effectiveness? Journal of Pragmatics, 43, 950-964. https://doi.org/10.1016/j.pragma.2010.07.033

Breiteneder, A. (2009). English as a lingua franca in Europe: an empirical perspective. World Englishes, 28(2), 256-269. https://doi.org/10.1111/j.1467-971X.2009.01579.x

Carter, R., Hughes, R., \& McCarthy, M. (2000). Exploring grammar in context. Cambridge: Cambridge University Press.

Cogo, A., \& Dewey, M. (2012). Analysing English as a lingua franca: a corpusdriven investigation. London: Continuum.

Crystal, D. (2003). English as a global language (2nd ed.). Cambridge: Cambridge University Press. https://doi.org/10.1017/CBO9780511486999

Dalton-Puffer, C., Kaltenboeck, G., \& Smit, U. (1997), Learner Attitudes and L2 Pronunciation in Austria. World Englishes, 16, 115-128. https://doi.org/10.1111/1467-971X.00052

Dewey, M. (2007a). English as a lingua franca: an empirical study of innovation in lexis and grammar. Unpublished doctoral dissertation, King's College, London.

ELFA (2008). The Corpus of English as a Lingua Franca in Academic Settings. Director: Anna Mauranen. Retrieved August, 11, 2014, from http://www.helsinki.fi/elfa/elfacorpus

Firth, A., \& Wagner, J. (1997). On discourse, communication, and (some) fundamental concepts in SLA research. The Modern Language Journal, 81 (3), 285-300. https://doi.org/10.1111/j.1540-4781.1997.tb05480.x 
Firth, A. (1996). The discursive accomplishment of normality. On "lingua franca" English and conversation analysis. Journal of Pragmatics, 26, 237-59. https://doi.org/10.1016/0378-2166(96)00014-8

Groom, C. (2012). Non-native attitudes towards teaching English as a lingua franca in Europe. English Today, 28(1), 50-57. https://doi.org/10.1017/S026607841100068X

House, J. (1999). Misunderstanding in intercultural communication: interactions in English as a lingua franca and the myth of mutual intelligibility. In C. Gnutzmann (Eds.), Teaching and learning English as a global language (pp.73-89). Tübingen: Stauffenburg.

House, J. (2002). Developing pragmatic competence in English as lingua franca. In K. Knapp and C. Meierkord (Eds.), Lingua franca communication (pp. 245-268). Frankfurt am Main: PeterLang.

House, J. (2003). English as a lingua franca: a threat to multilingualism?. Journal of Sociolinguistics, 7(4), 556-578. https://doi.org/10.1111/j.1467-9841.2003.00242.x

Jenkins, J. (2000). The phonology of English as an international language. Oxford: Oxford University Press.

Jenkins, J. (2005a). Implementing an international approach to English pronunciation: the role of teacher attitudes and identity. TESOL Quarterly, 38(3), 535-544. https://doi.org/10.2307/3588493

Jenkins, J. (2006a). Current perspectives on teaching World Englishes and English as a lingua franca. TESOL Quarterly, 40(1), 157-181. https://doi.org/10.2307/40264515

Kaçar, I. G., \& Bayyurt, Y. (2018). ELF-aware pre-service teacher education to promote glocal interactions: A case study in Turkey. In A. F. Selvi \& N. Rudolph (Eds.), Conceptual Shifts and Contextualized Practices in Education for Glocal Interaction - Issues and Implications (pp. 77-104). Singapore: Springer (ISBN: 978-981-10-6420-3). https://doi.org/10.1007/978-981-10-6421-0_5

Kaur, J. (2011). Raising explicitness through self-repair in English as a lingua franca. Journal of Pragmatics, 43, 2704-2715. https://doi.org/10.1016/j.pragma.2011.04.012

Kemaloğlu-Er, E., \& Bayyurt, Y. (2019). ELF-aware Pre-Service Teacher Education: Teaching Practices and Reflections from Turkey. In L. Cavalheiro (Ed.), Preparing English Language Teachers for Today's Globalized World (pp. 47-64). Lisbon: ULICES - University of Lisbon Center for English Studies.

Kirkpatrick, A. (2007a). World Englishes: implications for international communication and English language teaching. Cambridge: Cambridge University Press.

Lakoff, R. (1984). The pragmatics of subordination. In Brugman, C. \& Macauley, M. (Eds.), Proceedings of the 10th annual meeting of the Berkeley Linguistic Society (pp. 472-480). Berkeley: Berkeley Linguistics Society. https://doi.org/10.3765/bls.v10i0.1964

Llurda, E. (Ed.). (2005). Non-native language teachers: perceptions, challenges and contributions to the profession. New York, NY: Springer. https://doi.org/10.1007/b106233

Mauranen, A. (2006b). Signalling and preventing misunderstanding in English as a lingua franca communication. International Journal of the Sociology of Language, 177, 123-150. https://doi.org/10.1515/IJSL.2006.008

Mauranen, A. (2007). Hybrid voices: English as the lingua franca of academics. In Flottum, K. (Ed.), Language and Discipline Perspectives on Academic Discourse. Cambridge Scholars Publishing, Newcastle upon Tyne (pp. 243-259).

Meierkord, C. (2000). An analysis of non-native-/non-native small talk conversations in English. Linguistik Online, 5, $1 / 00$.

Murray, H. (2003). Swiss English teachers and Euro-English: attitudes to a nonnative variety. Bulletin Suisse de linguistique appliquee, 77, 147-165.

Önen, S. (2014). Lexico-grammatical features of English as a lingua franca: a corpus-based study on spoken interactions. Unpublished doctoral dissertation. Istanbul University, Istanbul.

Önen, S. (2015). The use of prepositions in English as lingua franca interactions: Corpus IST-Erasmus. Journal of Education and Practice, 6(5), 160-172.

Önen. S. (2016). Zero Marking in English as Lingua Franca Interactions: Corpus IST-Erasmus. Studies in English Language Teaching, 4(2), 208-222. https://doi.org/10.22158/selt.v4n2p208

Seidlhofer, B. (2001). Closing a conceptual gap: the case for a description of English as a lingua franca. International 
Journal of Applied Linguistics, 11(2), 133-158. https://doi.org/10.1111/1473-4192.00011

Seidlhofer, B. (2004). Research perspectives on teaching English as a lingua franca. Annual Review of Applied Linguistics, 24, 209-239. https://doi.org/10.1017/S0267190504000145

Seidlhofer, B. (2011). Understanding English as a lingua franca. Oxford: Oxford University Press.

Sifakis, N. C., \& Bayyurt, Y. (2016). Topic \& Comment. ELF-aware teacher education and transformative learning. Comments on Éva Illés. Journal of English as a Lingua Franca, 5(1), 147-153. https://doi.org/10.1515/jelf-2016-0007

Sifakis, N., Lopriore, L., Dewey, M., Bayyurt, Y., Vettorel, P., Cavalheiro, L., Siqueira, D. S. P., \& Kordia, S. (2018). ELF-awareness in ELT: Bringing together theory and practice. Journal of English as a Lingua Franca (JELF), 7(1), 155-209. https://doi.org/10.1515/jelf-2018-0008

Timmis, I. (2002). Native speaker norms and international English: a classroom view. ELT Journal, 56(3), 240-249. https://doi.org/10.1093/elt/56.3.240

VOICE Project. (2007). VOICE Transcription Conventions [2.1]. Retrieved June 21, 2013 from $\mathrm{http}: / / \mathrm{www} . u n i v i e . a c . a t / v o i c e / v o i c e . p h p ? p a g e=$ transcrition_general_information

VOICE. (2013). The Vienna-Oxford International Corpus of English (version 2.0 XML). Director: Barbara Seidlhofer; Researchers: Angelika Breiteneder, Theresa Klimpfinger, Stefan Majewski, Ruth Osimk-Teasdale, Marie-Luise Pitzl, Michael Radeka.

Walker, R. (2010). Teaching the pronunciation of English as a lingua franca. Oxford: Oxford University Press.

Young, T. J., \& Walsh, S. (2010). Which English? whose English? an investigation of "non-native" teachers' beliefs about target varieties. Language, Culture and Curriculum, 23, 123-137. https://doi.org/10.1080/07908311003797627 